\title{
DIDACTICAL MODELING - MAIN PREREQUISITE, CONDITION AND FACTOR FOR ENSURING QUALITY IN GEOGRAPHY EDUCATION
}

DOI: http://dx.doi.org/10.18509/GBP.2016.28

UDC: 37.02:91(497.2)

Assoc. Prof. Dr. Lucila Tzankova

Assist. Prof. Dr. Maya Vasileva

Assist. Prof. Dessislava Poleganova

Assist. Prof. Dr. Georgi Kotseff

Sofia University "St. Kliment Ohridski”, Faculty of Geology and Geography, 15 Tzar Osvoboditel blvd., Sofia, Bulgaria

\begin{abstract}
The contemporary geography didactics in Bulgaria is evolving through thorough study of the theoretical foundations and best practices in the countries with well-developed educational systems. Thus in our paper we examine the achievements of the German school of didactics and present the didactical modeling as main prerequisite, condition and factor for providing high quality planning, organization and implementation of the geography educational process. We have also focused on the analysis of basic didactical models and the opportunities to adapt them in the geography educational system in Bulgaria.
\end{abstract}

Keywords: geography education, geography didactics, geography modeling, geography training

Adherence to scientific criteria for quality is not only a necessary, but rather an obligatory condition for the implementation of any training process in contemporary education. That does not mean that a universal approach for carrying out training should or must be applied as it is a well known fact that many pathways lead to the final goal. That's why we connect the quality criteria with targeted, objective and rational planning, implementation and reflection of didactic activity as a whole and the process teachinglearning in particular. In relation with this, the role of didactic planning in reaching high quality and effectiveness of training (including geography training) is quite clear. Throughout the training process, the didactic models define requirements to the participants for fulfillment of specific criteria. Models are a prerequisite for the training process to be examined and explored from different scientific and theoretical point of view i.e. to be viewed from different didactic perspective. In order to achieve didactic competence for planning, reflection and activity/behavior model not only previous teaching experience is needed but also consultation and substantiation using theoretical concepts. Integrating theory and experience creates a precondition for the establishment of didactic competence for activity i.e. for the set up of didactic behavior model of trainers/teachers. But what makes training good? And how the learners and the teachers achieve their goals while applying a better and more innovative training process? These questions do not have a single and unequivocal answer. Furthermore, it is clear that training validation based on didactic principles is absolutely necessarily. This is so 
because the didactic principles manage the training activities and determine the way in which the training process should progress [1].

To proof our thesis in the current research we will examine in general the didactical models relevant to geography training.

Didactic models are scientific-pedagogical and theoretical constructions for analysis and modeling didactic activity in school and outside it [2], [3]. They explain and classify the factors which determine training, its forms, as well as the sequence of planning activities, training implementation and training analysis [4]. Didactic models are characterized by certain features (reduction, emphasis, transparency, perspective, productivity) which describe their capabilities but at the same time suggest the impossibility of a particular model to encompass all aspects of didactic activity in its entirety [4]. Didactic models as a result of scientific research of school reality represent different universal perceptions and thus they have significant practical importance covering specific functions: to structure and illustrate key factors in training; to outline the main nodes contributing for systematic planning and implementation of training; to clarify the circumstances, interrelations and impact of different behaviors of the teacher and the pupils [5]. As the training process is quite complicated, it will be difficult to use only one approach from a model or to combine several models. Simultaneous model usage is hardly possible due to relative autonomy and specific laws of each model. This means that the teachers should aim at continuous critical (problematic) review of the training process.

For the goals of our research we will refer to some didactic models which are of greater importance for geography didactics and can be applied in geography training namely: model of educational-theoretic didactics, model of critical-constructivist didactics, Berlin and Hamburg model, model of constructivist didactics.

The educational-theoretical and critical-constructivist models are built on the main concept of "education". In these models the person is considered in the context of his "educational activity". This activity is considered individual and is based on "value of the educated person" [5]. Educational-theoretical model is based on theory of "categorical education". According to it the person is able to make ratiocinations about the world using his knowledge. He is open-minded to reality thanks to his "categorical" viewpoint, experience and background [6]. Educational-theoretical didactics determines two concepts for education. The first is based on curriculum content and general matters that are of importance for the pupils' life, and the second - refers to the search for relations and competences with regard to activities that are considered important for the current and future life of the pupils [6]. The theory of "categorical education" [6] combines these two concepts and brings a new meaning to education. Education is envisaged as the evolution of a person throughout material and spiritual reality. In the terms of geography training this means searching for the answer of the question how the curriculum content i.e. the spatial reality of our world influences the learning subject and how at the same time the learning subject influences the world. Didactic analysis stands in the centre of the educational-theoretical model. It is perceived as the "core of education" revealing the educational content for a particular curriculum topic. Using didactic analysis we verify what curriculum content is actually needed for the pupils' everyday life nowadays and what will be important for their everyday life tomorrow [1]. Main guideline didactic questions for such analysis of the curriculum content and the training organization of a specific topic are: significance for present, significance for future, structure of curriculum content, "exemplar" value and accessibility [6]. These questions are the basis for transforming education and materializing it into given curriculum content. This model 
relies on one hand on the changes in the understanding of educational values and on the other hand - on the future opportunities for society and individual development that are unforeseen from today's standpoint. Insufficient bond with practice can be observed in this model in the context of training. This is a result from the high degree of model abstractedness, the relative negligence of the curriculum-methodical and organizational aspects of training and also the lack of coordination with the learner's starting point, interests, capabilities, etc. These disadvantages are overcome using the model of criticalconstructivist didactics [7]. The concept "education" in this model is again in the central position but at the same time it possesses a clear "emancipatory" direction. Following this model, education is aiming at the improvement of three main capabilities of the learners i.e. the ability for self-determination, co-association/affiliation and solidarity in all life aspects [7]. So in this model education is perceived as general literacy which determines the ability of a person to think critically, competently, consciously and jointly, to have such behavior and to evolve in such way" [2]. Education is considered an interactive process in which the pupils play the leading role, they communicate, interact, cooperate and enhance their strong character traits. Key aim in their development is primarily to develop the ability to communicate and cooperate, to creatively resolve problems and build-up one's humane attitude. It is suggested to achieve this goal by including (in curriculum content) contemporary "key problems" typical for the current time which can be considered as "hot spots" for the present and future social development on national and global scale. The framework of didactic analysis is substantially expanded in the critical-constructivist didactic and it is presented by "perspective scheme for training construction" [7]. According to it the training is built on the basis of "analysis of circumstances" and four complex questions - contextual rationale, themes structuring, defining accessibility and possibilities for presentation, methodical structuring. Two new aspects are added to these five didactic questions: possibility to verify/prove and structure of the teaching-learning process. And while the first ones pursue observation and ascertainment of training achievements, the second ones are looking at teaching methods and also at "social learning". The presented perspective framework is reduced according to the "catalog" of key problems. The two didactic models could not be combined in one universal "recipe" for didactic activity and are rather defined as "supporting reflection and problematization" [2].

The emergence of a theoretical model for teaching and learning is result from the criticism of the educational-theoretical didactics of Klafki [8]. The model has evolved from the so-called "Berlin" to the so-called "Hamburg" model. The Berlin model is based on the idea to encompass the so-called "skeleton" of every lesson i.e. to derive all structural elements that can have influence and which are formal and constant and subject them to scientific control. The goals, curriculum content, methods and sources of information are all parts of these constant elements in every lesson/training process. For the planning and implementation of every lesson, the teacher should always make decisions on what is new in these four constants which constitute "area of decision making". As these constants are decision making factors for each lesson, they are implicitly interrelated because every single decision taken by the teacher for a given structural element has impact on all others. Therefore all the decisions of the teacher are also interconnected. Since training is an "integral part of complex life reality" [1] it is influenced by situational conditions (social-cultural) which influence the participants in training activities (anthropological/psychological conditions). Psychological conditions (primarily of pupils, teachers, parents) and social-cultural conditions (mainly 
social/family, economic, political, historical-cultural) build the so-called "circumstances field". The training activity in the area of decision making has impact on both the socialcultural and on the anthropological-psychological sphere. The situational conditions which are changed as a result of training "overflow" again in a new circumstances analysis. Whereas the decision factors and their interrelations are necessary for every single lesson, the circumstances analysis is needed as a rule only in the beginning of a new curriculum unit. The structural "building" of training is considered as a planning instrument as well as an instrument for performing training analysis.

The Berlin model is criticized mainly for ignoring the basic goals for education and upbringing, for the teacher-centered focus, as well as for ignoring the importance of interpersonal relations in the training process (not only between teacher and pupils but also among the pupils themselves). As a result of these criticisms, the Berlin model was improved by focusing training to "emancipation" aims - competence, autonomy, solidarity i.e. through activity orientation (Hamburg model). Unlike the Berlin model which is considered as "decision model", the Hamburg one is perceived as an "activity model". The decisions related to the training process are not determined entirely by the teacher's overall competences any more, but the training planning is a result of the joint work of all participants. Thus the pupils are no longer the mere object of education but also become subjects in the process. Hence didactic activity focuses on the activity component of training, on the interaction between teacher and pupils with regard to curriculum goals; on the starting point and variables in the training process and the control of training achievements. The process teaching-learning is influenced on one hand by the institutional conditions (curriculum program, educational standards, specialized conferences, school environment) and on the other hand - by society framework conditions (business activity, official authorities' attitude, self-understanding and perception of the world of all participants of school-related activities) [9]. The model is focused on answering the following four didactic questions:

- What must to be taught/learnt? This is related to the aims of training which, in turn, are related not only to the general goals but also to topics/curriculum content.

- Who learns and from whom? Beginning with the participants' starting point in training (pupils and teacher), their motives, previous experience, knowledge and opinions.

- How this is done, using which training options (methods, forms, sources of information)?

- How to assess if training is successful - control of results? How we determine and measure progress in training? Who will measure and verify? [3]

Another important feature and innovation in the Hamburg model is the four levels of training planning:

- In perspective planning the training is constructed for a longer time period (one year or one school term) compared to the course of teaching and study units;

- In general planning (sketching a general plan view) specific "didactic-methodical" groups are structured and ordered in study units;

- In procedural planning the focus is centered on training in a particular training class;

- Corrective planning is carried out during particular events in the training process and in case of unexpected development.

The referred levels express the variability respectively flexibility of training [2].

The educational-theoretical model of Klafki [6,7] and the Berlin model of Heimann, Otto $\&$ Schulz [8] are based on different scientific and theoretical grounds. This is mainly due 
to the fact that the authors have created these models during times of continuous change and divergence of the didactic concepts for training and lessons. The Hamburg and the critical-constructivist models are examples of criticism to the above-mentioned models. As they have been developed on the basis of almost the same scientific and theoretical perspective, so that allows their integration [1]. The theoretical and practical differences between the two improved models are gradually diminishing in past years and some compatibility could be observed. The following common features could be pointed out:

- Primary importance of goal setting in comparison with the other factors for decision making (curriculum content, methods, sources of information);

- The implicit interrelation between the factors that construct the process of training;

- The pupils as subject of training, their needs, interests, problems etc.

The educational-theoretical and theoretical model of teaching and learning could find their application in planning as well as in analysis and reflection in the geography training in Bulgaria. They could be especially useful for students, interns and young teachers when they structure and methodically develop their lessons.

In comparison with other models, the constructivist didactic model is most focused on the individual participation of the person in the training process. Learning is no longer considered the mere consequence of teaching but the result of "individual constructive achievement of the learner" [2]. Pupils are no longer passive receivers of information. They are active, self-governing learners. They have the ability to plan their study, to organize, implement and assess it. In turn, the teacher is less the mediator of knowledge and more - the assistant supporting the training process [10]. Here the methodical variety, individual approach, activity orientation are defined as the "backbone" supporting the methodical construction of the training process. With reference to written above great expectations are imposed to the mentioned didactic model for increasing the effectiveness of the training process. We accept these notions but only in the framework of "moderate constructivism." The model can be criticized for the fact that the "moderate constructivism" does not offer strict mechanisms for notion change. Nevertheless, this concept for learning may clearly influence the organization of geography training process as well as be considered in geo-didactic scientific researches.

TO SUMMARIZE: Do we need the presented didactical models of planning, accomplishment and reflection in geography training and to what extend? To answer this question we should look at each of them again.

The two educational-theoretical models developed by Klafki [6,7] provide geography teachers with the necessary instrument and means to identify the geography topic of the training and to revise the specifics of geography educational content. The proficiency in such kind of competence is very important for two reasons. On one hand, geography science constantly develops and improves dealing with new problem cases and questions and generates new topics for geography training (curriculum content). On the other hand, taking into consideration that geography syllabus is focused on acquiring competence, the suggested topics in the curriculum content should provide opportunities for decision making in the present as well as in the future, and for taking responsibility and achieving higher levels of independent thinking and attitudes.

The theoretical models for teaching and learning provide the geography teacher with the so-called "backbone" for every lesson. The model's potential is primarily due to the fact that they clearly outline implicit interrelations between the four factors for decision 
making (aims, curriculum content, methods and sources of information). Finding the balance between the aim - curriculum content level and the methodical - information one for each lesson has very high value for geography training because geography as curriculum subject possesses significant informational and methodical dynamics. The geography training process utilizes a variety of educational methods, traditional and unconventional sources of information, modern digital information and communication technologies. It is very difficult to deal with everyday situations/problems in contemporary society without wide communication, information and methodical competence nowadays and it will get harder in the future. Geography training contributes to the formation and development of skills and abilities important for the learner's everyday life.

The widening of the scientific debate about constructivism leads to the wide-spread concept that reaching proficiency in science is an individual process which occurs in a different way for each person. Constructivism offers the theoretical framework for analysis and encouragement of the process of acquiring scientific knowledge in different social context [11]. A fundamental aim of geography training is to acquire knowledge about the interrelations between the natural environment and the social activities in different areas on Earth and on the basis of that knowledge to provide for the setup of different activity competences and behavior models in geographical space. The space is deliberately examined through four different perspectives [12]:

- In realistic sense - as container;

- As system of spatial interrelations of material objects;

- As perception category;

- According to the perspective of its social, technical and social constructiveness [12].

With regard to the above, the geography training provides the opportunity for the pupils to encounter different spatial perspectives, to perceive them, to reflect them critically, to evaluate them and thus to construct their own individual view of the world. That is the why constructivist didactics has no less importance for geography training than the previously discussed models.

The integration of the three models, despite the underlying different viewpoints, will guarantee the most precise goal setting in geography training and will allow the maximum compliance with the level of knowledge in the learning process. The comprehensive consideration of didactical models, as well as their implementation in practice will offer to geography education in Bulgaria the so needed basis for the creation of a geography specific didactical model as well as for its implementation in the process of teaching.

\section{REFERENCES}

[1] Otto, K.-H. Didaktische Modelle und Prinzipien. - In: Haversath, J.-B. (2012): Geographiedidaktik. Theorie-Themen-Forschung. Braunschweig: Westermann, pp 3755, 2012.

[2] Jank, W. \& Meyer, H. Didaktische Modelle. Berlin: Cornelsen, 1991/2002/2003.

[3] Gudjons, H. Erziehungswissenschaft kompakt. Hamburg: Bergm. u. Helb., pp 145, 151-152, 1999.

[4] Köck, P. Handbuch der Schulpädagogik für Studium - Praxis - Prüfung. Donauwörth: Auer, pp 149, 2000. 
[5] Rinschede, G. Geographiedidaktik. (3.Aufl.), Paderborn u.a.: Ferdinand Schöningh, pp 37, 2007.

[6] Klafki, W. Kategoriale Bildung. Zur bildungstheoretischen Deutung der modernen Didaktik. - In: Klafki, W.: Studien zur Bildungstheorie und Didaktik. Weinheim/Basel, pp 25-45, 298, 1963.

[7] Klafki, W. Neue Studien zur Bildungstheorie und Didaktik. Zeitgemäße Allgemeinbildung und kritisch-konstruktive Didaktik. Weinheim/Basel, 1985/1996.

[8] Heimann, P., Otto, G. \& W. Schulz. Unterricht - Analyse und Planung. Hannover, 1965.

[9] Schulz, W. Unterrichtsplanung. München, Wien, Baltimore, 1981.

[10] Gudjons, H. Pädagogisches Grundwissen. Bad Heilbrunn: Klinkh, 2003.

[11] Gerstenmaier, J.\&H. Mandl. Wissenserwerb unter konstruktivistischer Perspektive. - In: Zeitschrift für Pädagogik, 41, 6, pp 867-888, 1995.

[12] Deutsche Gesellschaft für Geographie (DGFG). Bildungsstandards im Fach Geographie für den Mittleren Schulabschluss - mit Aufgabenbeispielen. Bonn, 2010. 